\title{
MASS AND MOMENTUM BALANCE MODEL OF A MIXED FLOWING/POWDER SNOW AVALANCHE
}

\author{
B. TURNBULL* and P. BARTELT \\ WSL, Swiss Federal Institute for Snow and Avalanche Research SLF, Flüelastrasse 11, 7260 Davos \\ Dorf, Switzerland \\ *E-mail: turnbull@slf.ch
}

(Received 5 December 2002; Accepted 18 March 2003)

\begin{abstract}
This work uses a one-dimensional, depth averaged model to compute the mass balance of a mixed flowing/powder snow avalanche. This model is comprised of three basic components: the dense flowing avalanche, the powder cloud and a turbulent wake. The dynamics of a mixed avalanche is strongly dependent on the interaction between the components and also on the snow cover and ambient air, in particular the exchange or entrainment of snow and air mass. Therefore, an important first step for modelling mixed avalanches is a basic understanding of the nature of these mass exchanges. In this paper, the governing equations of mass, momentum and turbulent energy are briefly presented. Numerical simulations were run for three avalanche tracks - Aulta, Galtür and Vallée de la Sionne - for which data from real snow avalanche events exist. Based on the results, conclusions were drawn regarding the parameterisation of the mass exchanges. The mass balances for these three contrasting avalanches are presented.
\end{abstract}

Keywords: entrainment, granular flows, gravity currents, mass balance, numerical modelling, snow avalanches

\section{Introduction}

Flowing and powder snow avalanche dynamics models are used by engineers and land planners to predict run-out distances, flow velocities and impact pressures of avalanches. Dense flowing avalanche dynamics models are based on the numerical solution of the depth averaged Navier-Stokes equations and are used in many mountainous countries (Christen et al., 2002). Although snow cover entrainment is neglected (Sovilla and Bartelt, 2002), the friction parameters of these models appear to be well enough calibrated that reasonable predictions of flow behaviour are possible once the starting conditions (initial mass) have been defined.

However, the application of powder snow avalanche models is not so advanced. Physical problems must be solved before these models can be used by practitioners with confidence. The life-cycle of a powder avalanche - the initiation, evolution and run-out - is dominated by mass exchanges with the snow cover, the ambient air and the dense flow. An accurate description of powder avalanche dynamics is impossible without modelling entrainment and deposition processes. 
Unfortunately, little experimental information is available to help researchers directly examine mass exchange processes. Information must be inferred from measured flow velocities, heights and impact pressures.

The purpose of the present work is to study the mass balance of "mixed" flowing/powder snow avalanches. Three documented avalanches, Aulta (1984), Galtür (1999) and Vallée de la Sionne (1999) are simulated. For these events either flow velocities have been recorded or post-event analyses were performed where impact pressures were deduced.

We study mixed avalanches because we are interested in predicting the initiation of a powder cloud from a dense flow. Our goal is to develop a unified flowing/powder snow avalanche model that can simulate both limiting cases of a pure flowing or powder avalanche.

The depth averaged governing differential equations of mass, momentum and energy are stated. This step introduces the free parameters defining air and snow cover entrainment. An overview of the mass exchange processes involved in a mixed flowing/powder snow avalanche (Section 3) qualitatively introduces concepts on which the model mass exchanges are based. The latter part of the paper discusses the results of the simulations.

\section{Mathematical Formulation}

Rather than using a computationally intensive model for turbulent flows, a similar approach to Parker et al. (1986) has been adopted. In their work, mass and momentum equations were solved for particle laden turbidity currents; the introduction of a turbulent energy equation allowed the system to be closed.

Mass and momentum balances are written for each component of the avalanche - the dense flowing avalanche, the powder cloud and the turbulent wake; the latter together make up the powder snow avalanche. In addition to the mass transfers between the components, the entrainment of snow cover and ambient air are included. A turbulent energy equation for the powder avalanche is required to close the system. On the right hand side of the powder cloud momentum equation, the drag coefficient, $C_{d}$, is dependent on turbulent kinetic energy $K_{p}$. In addition, the entrainment of air into the turbulent wake is a function of turbulent kinetic energy $K_{w}$. Table I gives the basic notation; Tables II and III present the notation used for the main avalanche characteristics.

\subsection{MASS CONSERVATION EQUATIONS}

$$
\begin{aligned}
& \partial_{t} h_{f}+\partial_{s}\left(h_{f} U_{f}\right)=\frac{\rho_{c}}{\rho_{f}} \dot{S}_{c \rightarrow f}-\dot{S}_{f \rightarrow p}-\dot{S}_{f \rightarrow d}, \\
& \partial_{t}\left(\rho_{p} h_{p}\right)+\partial_{s}\left(\beta_{p} \rho_{p} h_{p} U_{p}\right)=\rho_{c} \dot{S}_{c \rightarrow p}+\rho_{f} \dot{S}_{f \rightarrow p}+\rho_{a} \dot{S}_{a \rightarrow p}-\rho_{p} \dot{S}_{p \rightarrow w},
\end{aligned}
$$


TABLE I

Basic notation

\begin{tabular}{ll}
\hline Symbol & Definition \\
\hline$h$ & Height \\
$u$ & Velocity \\
$U$ & Depth-averaged mean velocity \\
$\rho$ & Density \\
$S$ & Volume \\
$M$ & Mass \\
$K$ & Turbulent kinetic energy density \\
$f$ & Dense flow \\
$c$ & Snow cover \\
$d$ & Deposits \\
$p$ & Powder cloud \\
$a$ & Ambient air \\
$w$ & Turbulent wake \\
\hline
\end{tabular}

TABLE II

Notation for the mixed avalanche model

\begin{tabular}{ll}
\hline Symbol & Definition \\
\hline$V$ & Viscous dissipation \\
$G$ & Turbulence generation \\
$\alpha$ & Profile integration factor \\
$\beta$ & Profile integration factor \\
$F_{g}$ & Dense flow driving force \\
$F_{d}$ & Dense flow drag \\
$D_{g}$ & $\Delta \rho g h_{p}$ Powder cloud driving force \\
$D_{d}$ & $C_{d} U_{p}^{2}$ Powder cloud drag \\
$D_{h}$ & Powder cloud hydrostatic driving force \\
\hline
\end{tabular}

$\partial_{t}\left(\rho_{w} h_{w}\right)+\partial_{s}\left(\beta_{w} \rho_{w} h_{w} U_{w}\right)=\rho_{p} \dot{S}_{p \rightarrow w}-\rho_{w} \dot{S}_{w \rightarrow d}$

\subsection{Momentum Equations}

$$
\begin{aligned}
& \partial_{t}\left(h_{f} U_{f}\right)+\partial_{s}\left(\alpha_{f} U_{f}{ }^{2} h_{f}\right)=F_{g}-F_{d}, \\
& \partial_{t}\left(\beta_{p} \rho_{p} h_{p} U_{p}\right)+\partial_{s}\left(\alpha_{p} \rho_{p} U_{p}{ }^{2} h_{p}\right)=D_{g}-D_{d}+D_{h} .
\end{aligned}
$$


TABLE III

Summary of mass/volume exchanges in a mixed avalanche. The first subscript denotes where the mass is coming from; the second subscript, after the arrow, denotes to where the mass is going.

\begin{tabular}{lll}
\hline Volume rate & Mass rate & Definition \\
\hline$\dot{S}_{f \rightarrow p}$ & $\dot{M}_{f \rightarrow p}=\rho_{f} \dot{S}_{f \rightarrow p}$ & $\begin{array}{l}\text { Snow ejected from the dense flowing avalanche into } \\
\text { powder cloud. Controlled by dimensionless parameter } E_{f p} .\end{array}$ \\
$\dot{S}_{c \rightarrow f}$ & $\dot{M}_{c \rightarrow f}=\rho_{s} \dot{S}_{c \rightarrow f}$ & Snow cover entrained by the dense flowing avalanche. \\
$\dot{S}_{f \rightarrow d}$ & $\dot{M}_{f \rightarrow d}=\rho_{f} \dot{S}_{f \rightarrow d}$ & Dense flowing avalanche deposition. \\
$\dot{S}_{c \rightarrow p}$ & $\dot{M}_{c \rightarrow p}=\rho_{s} \dot{S}_{c \rightarrow p}$ & Snow cover entrained by the powder cloud. \\
$\dot{S}_{a \rightarrow p}$ & $\dot{M}_{a \rightarrow p}=\rho_{a} \dot{S}_{a \rightarrow p}$ & Air entrained by the powder cloud: \\
& & function of the Richardson number, $R i$, \\
& & and the dimensionless parameter $E_{a p}$. \\
$\dot{S}_{p \rightarrow w}$ & $\dot{M}_{p \rightarrow w}=\rho_{p} \dot{S}_{p \rightarrow w}$ & Powder cloud to turbulent wake exchange: \\
$\dot{S}_{w \rightarrow d}$ & $\dot{M}_{w \rightarrow d}=\rho_{w} \dot{S}_{w \rightarrow d}$ & based on critical density, $\rho_{c}$. \\
\hline & & Powder avalanche deposition. \\
\hline
\end{tabular}

\subsection{TURBulent ENERGy EQUATIONS}

$$
\begin{aligned}
& \partial_{t}\left(h_{p} K_{p}\right)+\partial_{s}\left(h_{p} U_{p} K_{p}\right)=\dot{G}_{p}-\dot{V}_{p}-\frac{\dot{S}_{p \rightarrow w}}{S_{p}} K_{p}, \\
& \partial_{t}\left(h_{w} K_{w}\right)+\partial_{s}\left(h_{w} U_{w} K_{w}\right)=\frac{\dot{S}_{p \rightarrow w}}{S_{p}} K_{p}-\dot{V}_{w} .
\end{aligned}
$$

A computer model is being developed to describe the dynamics of mixed flowing/powder snow avalanches. The main objective of this software is to provide a user friendly way of helping the assessment of the hazard posed by mixed avalanches on a particular track. In order to do this, it is necessary to solve the stated advection diffusion equations for each component of the mixed avalanche (Turnbull and Bartelt, 2002). These one-dimensional, depth averaged equations are programmed using an upwinded TVD finite difference scheme (Sartoris and Bartelt, 2000).

\section{Mass Exchanges}

Mass exchange processes between the avalanche components, the snow cover and the air (Table III) have a huge significance for the development of a mixed avalanche. Figure 1 shows the components of a mixed avalanche and the exchanges. 


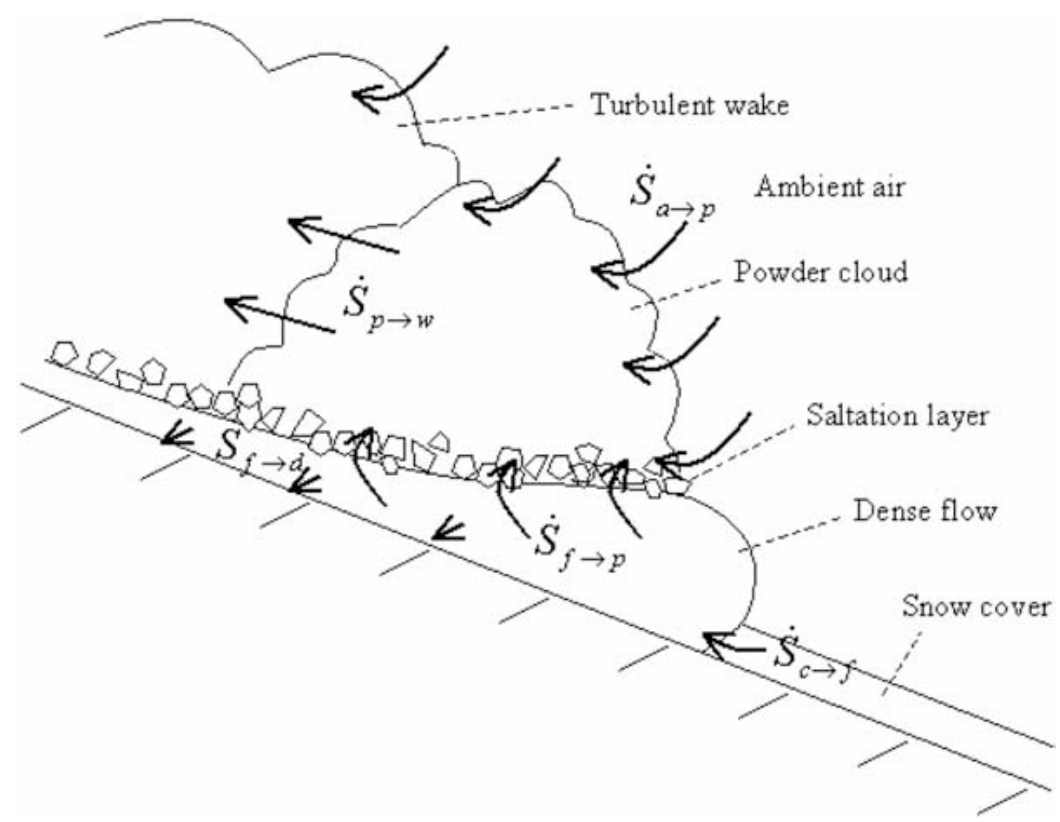

Figure 1. Diagram showing the components and exchanges in a mixed flowing/powder snow avalanche.

The dense avalanche is a granular flow of snow, the dynamics dominated by inter-particle collisions and a basal shear layer (Norem et al., 1987; Dent, 1993). Field studies have shown that the mass of a dense flowing avalanche can multiply several times by entraining snow cover (Sovilla and Bartelt, 2002). Mass is lost from the dense flow by deposition and from saltating snow that entrains air to become the powder snow suspension.

The quantity of snow entrained from the dense flow into suspension and the suspension's excess buoyancy compared with the surrounding air defines whether or not a powder snow avalanche initiates. If the excess buoyancy is sufficient to overcome inertia and the turbulent energy sufficient to maintain the suspension, the suspension will start to flow. Continued snow entrainment - from the dense flow and directly from the snow cover - feeds the powder avalanche and increases the driving force. Entrainment of ambient air and snow particle deposition reduce the powder avalanche density and reduce the driving force. The balance of these effects determines whether the powder avalanche accelerates or slows down, and so determines its run-out distance and velocities.

Regions where the excess density is insufficient to drive the powder suspension are assumed to no longer play a dynamical role in the propagation of the avalanche and are considered part of the "turbulent wake". The turbulent wake is apparent when observing a powder avalanche; after the head of the powder avalanche has passed, the suspension continues to entrain air but has very little downslope motion. 
Three mass exchanges are central to the evolution of a mixed flowing/powder snow avalanche - snow cover entrainment, dense flow to powder cloud exchange, and powder cloud air entrainment.

Each of these mass exchanges requires some free parameter to quantify them. This is a result of both the requirements of a simple numerical model - to be operational with minimal computer resources and know-how - and the relatively small amount of precise knowledge of the physical processes involved. Detailed experiments and research into individual aspects of mixed snow avalanche mass exchanges will in the future reduce the reliance of such models on free parameters. For now, by comparing the model results with a variety of data from mixed avalanche events, ranges can be put on these free parameters. A next step is to use these studies to make predictions on avalanche tracks where instrumentation is installed (real, or in the laboratory). A full description of the mass exchange functions, including definitions of $E_{f p}$ and $E_{a p}$, can be found in Turnbull and Bartelt (2002).

In the following discussions only the dense flow to powder cloud exchange and powder cloud air entrainment are considered. Snow cover entrainment is not varied between simulations; however, it should be appreciated that, if the powder cloud is ahead of or wider than the dense flow, snow cover will be entrained directly into the powder cloud. Other mass exchange processes are independent of free parameters, such as particle deposition and creation of the turbulent wake (Turnbull and Bartelt, 2002). Parameters in the momentum equation are kept constant at values determined by calibration of similar numerical models (Christen et al., 2002; Bartelt et al., 1999).

\section{Simulations}

To investigate the effect of mass exchange parameters on a mixed avalanche computer simulation, the described one-dimensional numerical model was run over a range of parameters on tracks where experimental data are available. Three tracks are of particular interest since the avalanches that occurred there had distinct features which help to classify the range of the studied parameters.

Initially simulations were run for the track Aulta in the Swiss Canton of Graubünden. A dense flowing avalanche which developed a small powder part occurred here on February 8, 1984 (Gubler et al., 1986). The data from this track enable an estimation of the exchange coefficient from the dense flow to a small powder cloud.

Considering the other end of the dense flow to powder cloud exchange range, the February 23, 1999 avalanche at Galtür in Austria was studied. After the initial stages, this avalanche was almost entirely a powder snow avalanche (Margreth, 2000) so its dynamics were primarily determined by the entrainment of ambient air. 
The Vallée de la Sionne (SLF test site in the Swiss Canton of Wallis) avalanche of February 10, 1999 contrasted with both the previous examples. A dense flow and highly developed powder avalanche coexisted creating an "extreme" mixed avalanche. The air entrainment coefficient, estimated from the Galtür simulations, and an intermediate dense flow to powder exchange coefficient were combined and compared with data (Dulfour et al., 2000).

For all of these avalanche events the fracture height and the depth of entrained snow cover were known from photogrammetric and field observations.

\subsection{Aulta}

The avalanche on February 8, 1984 was released from the North side of the Val Aulta and ran East-South-East into the Val Medel. The Lukmanier pass road (closed for the winter) was buried for more than $100 \mathrm{~m}$ by $5 \mathrm{~m}$ of snow. The avalanche continued and ran up the opposite slope; it and was described by observers as a dry dense flowing avalanche with a small powder part (Gubler et al., 1986).

A microwave Doppler radar with a frequency range of $8-12 \mathrm{GHz}$ measured the maximum velocities within the avalanche. Simulations were run for a range of dense flow to powder exchange coefficients, $E_{f p}$. By comparing the simulation maximum velocities with the Doppler radar velocity measurements a typical value of $E_{f p}$ for a dense flowing avalanche with a small powder part could be found. Since the powder cloud was small, air entrainment is assumed to have relatively little effect and this coefficient was kept constant at an intermediate value, $E_{a p}=$ 1.0 .

How the maximum velocity of an avalanche varies with $E_{f p}$ is shown in Figure 2. Figure 3 shows the velocities of the avalanche that fit closest to the Doppler radar data over the track length; this corresponds to an exchange coefficient $E_{f p}=$ $2.5 * 10^{-4}$. The velocities fitting closest with the data are in the powder cloud since the frequency of the radar signal corresponds to a wavelength of a few nanometers; the particles the radar "sees" will also be of this scale. This size of particle is usually found in the powder suspension.

The Aulta avalanche mass balance (Figure 4) shows that, although more than doubling its total mass, the avalanche remains mostly a dense flowing avalanche, in agreement with the observations.

\subsection{GALTÜR}

In the first months of 1999, the combination of an unprecedented quantity of snow and weather conditions over the winter led to many seriously destructive avalanches (Margreth, 2000). One was in the Austrian village of Galtür, where a number of buildings were destroyed and there was a heavy loss of life. The seriousness of this avalanche meant that the resulting debris was closely examined to find out how and why the accident was so catastrophic. 


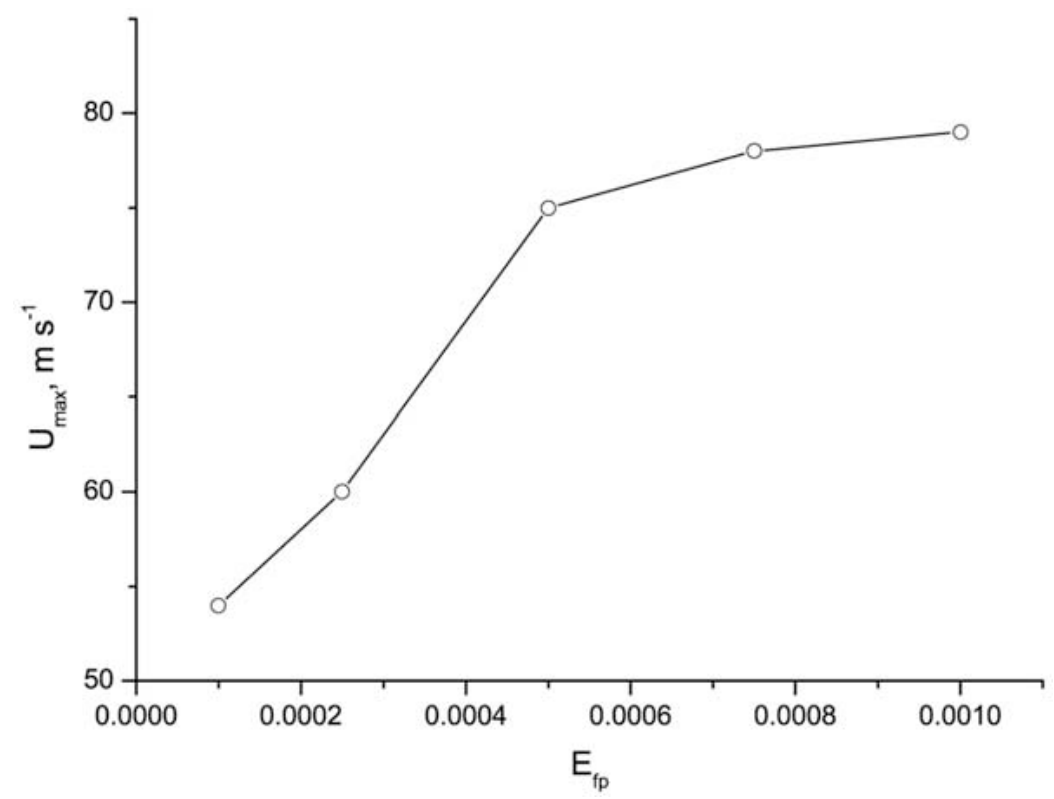

Figure 2. Variation of simulation maximum velocities with dense flow to powder exchange coefficient, $E_{f p}$. Aulta avalanche, February 8, 1984.

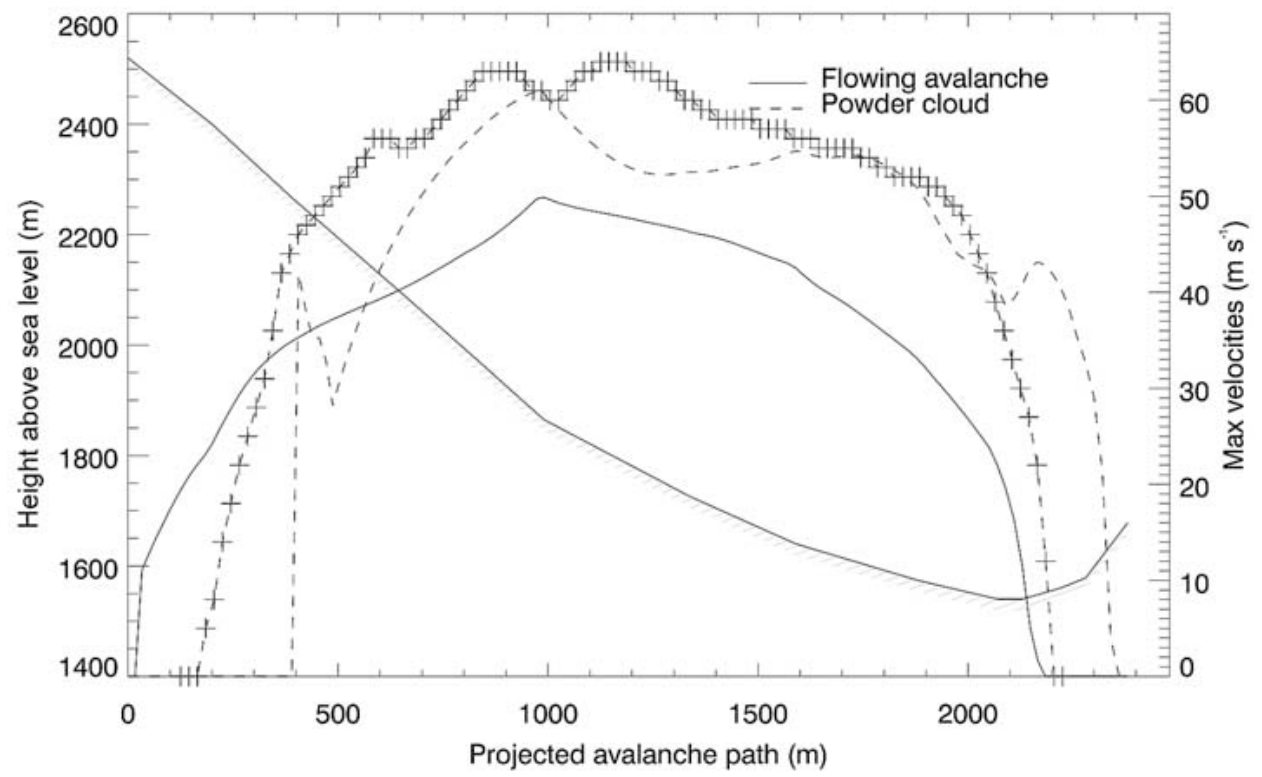

Figure 3. Simulated and measured maximum velocities (right hand scale) of Aulta avalanche, February 8,1984 . The dashed line with cross marks shows the Doppler radar measurements. The solid line with dots underneath shows height along the avalanche path. 


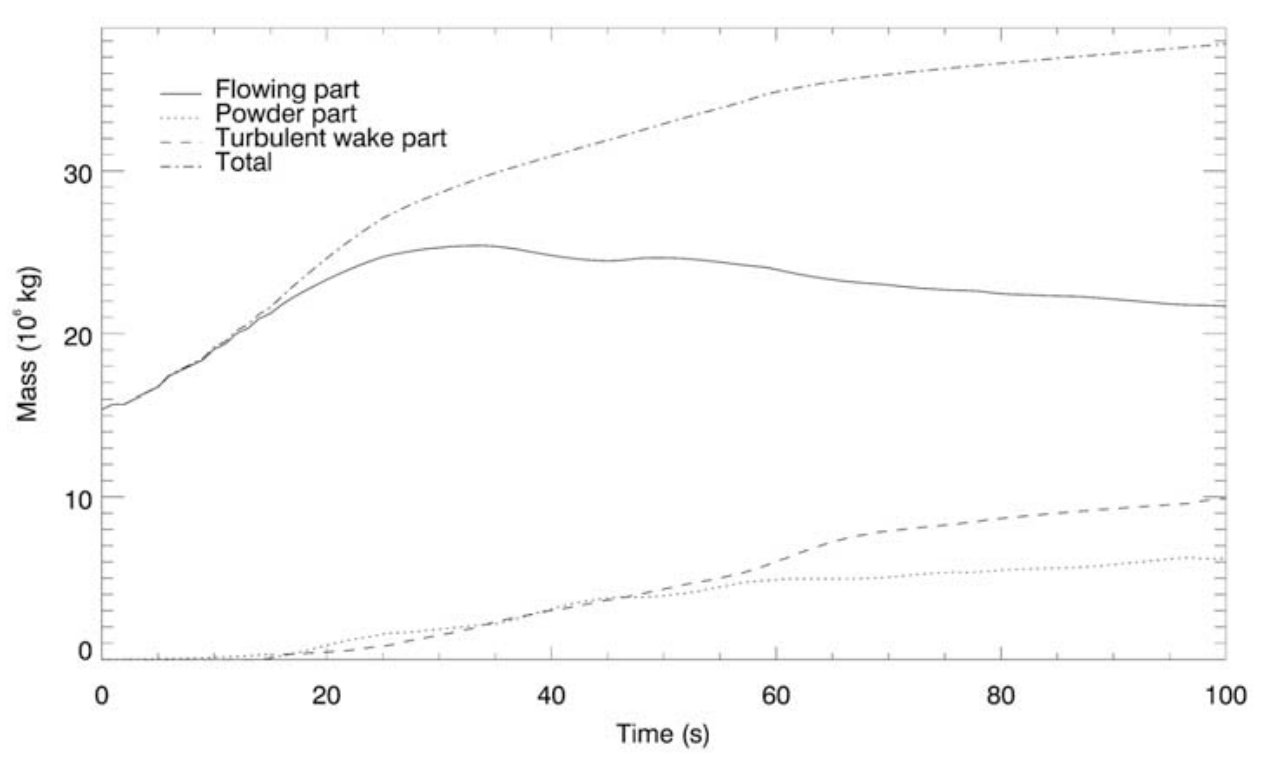

Figure 4. Simulated mass balance of Aulta avalanche, February 8, 1984. $E_{f p}=2.5 * 10^{-4}$.

One way in which the debris was analysed was by calculating the pressures necessary to cause the observed damage, such as lifted house roofs (Margreth, 2000). For example, estimations based on the damage to Haus Litzner (1585 m a.s.l.) indicated maximum impact pressures of $47.3 \mathrm{kPa}$. The avalanche deposits were almost entirely those typical of a powder snow avalanche; these are wind packed fine ice particles with ripple patterns. From this evidence it was concluded that after the initial stages the avalanche was a pure powder snow avalanche. It was assumed that the dynamics were independent of $E_{f p}$ since there was no dense flow. By running simulations with a high value of $E_{f p}=0.1$, the relationship between the powder pressure at the position of Haus Litzner and the air entrainment coefficient, $E_{a p}$, could be found. Figure 5 shows this relationship together with the estimated exerted pressure at Haus Litzner for the February 23, 1999 avalanche.

For the simulated avalanche to exert a pressure of $47.3 \mathrm{kPa}$ at $1585 \mathrm{~m}$ a.s.l., the air entrainment coefficient $E_{a p}=0.65$. The mass balance for this simulation (Figure 6) shows that, in agreement with the observations, the dense flowing avalanche disappears almost immediately and an almost pure powder snow avalanche evolves. The total avalanche mass increases almost 7 times over its course.

\subsection{VAllée de la Sionne}

On February 10, 1999 a very large avalanche was released at the Vallée de la Sionne test site in Western Switzerland. Video recordings were taken from two different locations and from these the front location of the avalanche could be deduced (Dufour et al., 2000). Integration over the time of a frame gave the front velocity. 


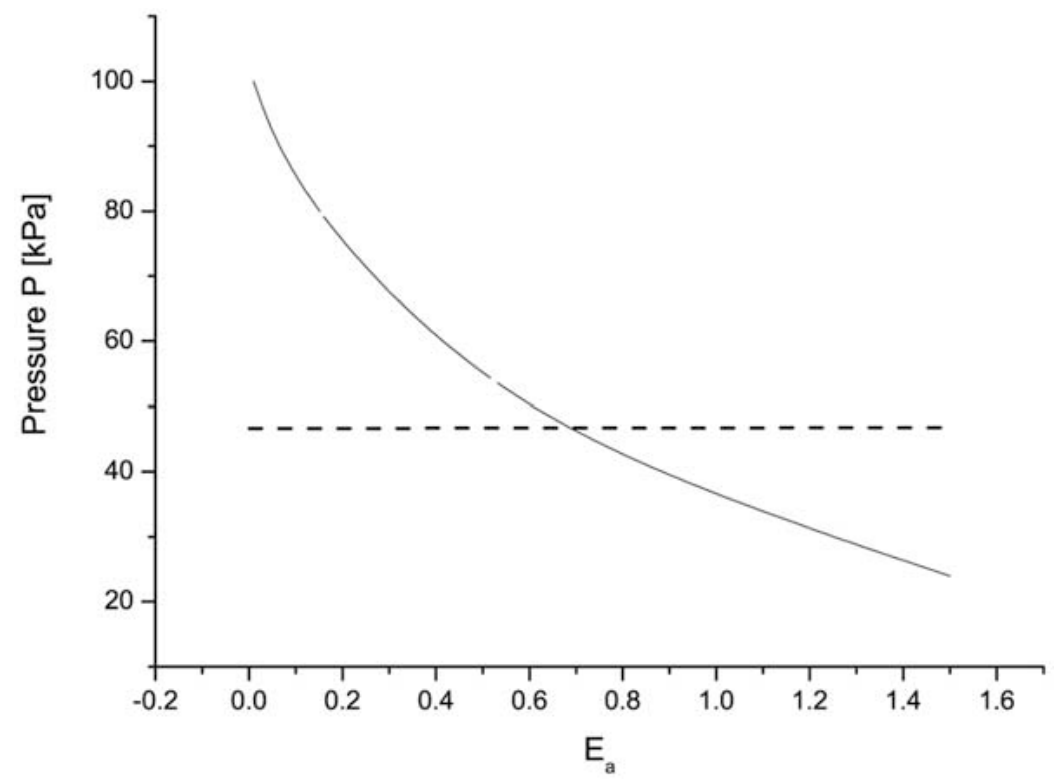

Figure 5. Variation of simulation impact pressures with air entrainment coefficient, $E_{a p}$, at the position of Haus Litzner (1585 m a.s.l.). Galtür avalanche, February 23, 1999.

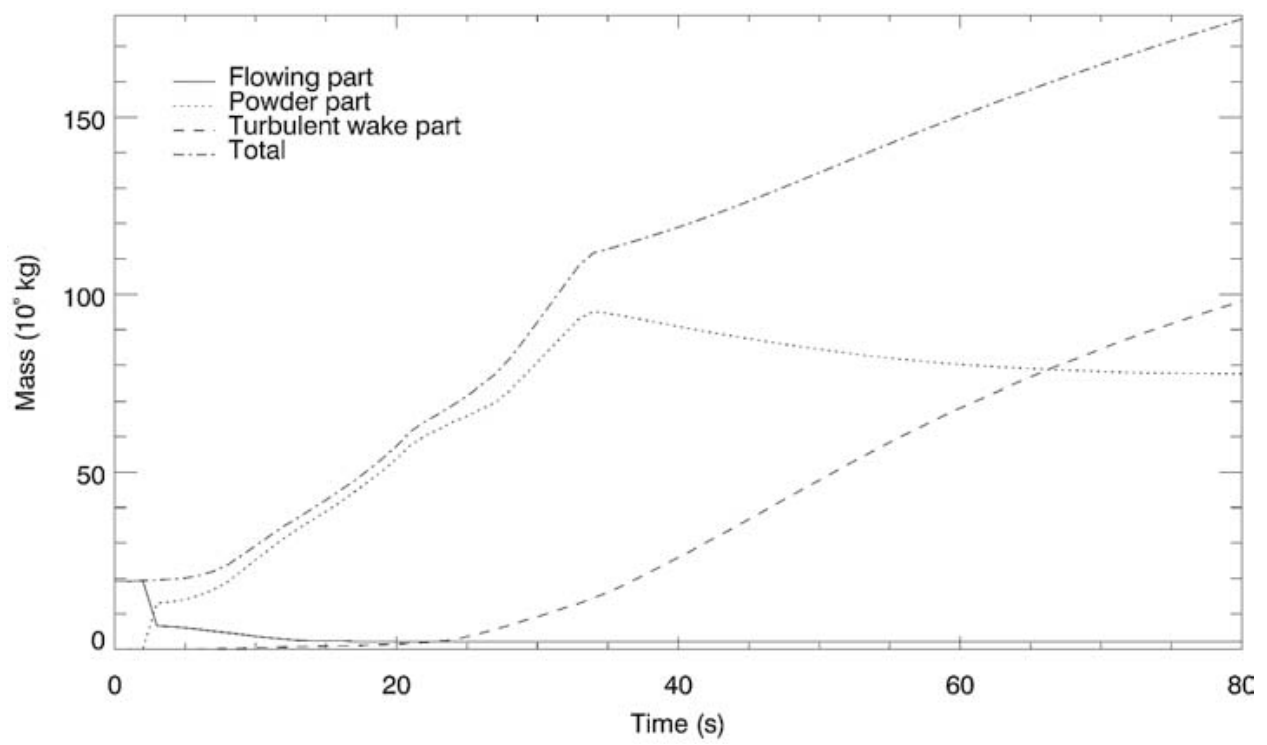

Figure 6. Simulated mass balance of Galtür avalanche, February 23, 1999. $E_{a p}=0.65$. 


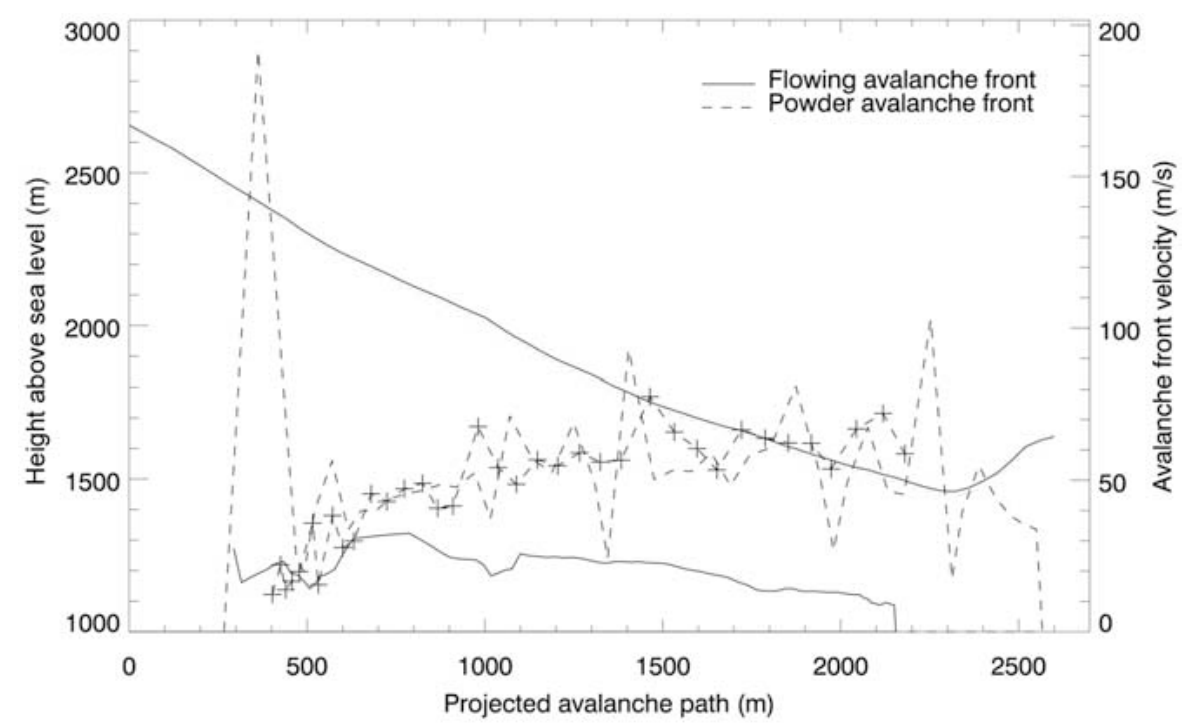

Figure 7. Simulated and measured front velocities of Vallée de la Sionne avalanche, February 10, 1999. The dashed line with cross marks shows the video measurements.

The videos and the type of snow deposits showed that not only was there a highly developed powder avalanche, but also a massive dense flow beneath it.

The air entrainment into this powder cloud was assumed to be comparable with that of the similar scale Galtür powder avalanche. Simulations for the 1999 Vallée de la Sionne track were run with the air entrainment coefficient found from the Haus Litzner (Galtür) impact pressure estimations, $E_{a p}=0.65$. An intermediate value of dense flow to powder exchange coefficient was selected: $E_{f p}=5 * 10^{-3}$, higher than that for the Aulta avalanche, but lower than the Galtür value.

The simulation front velocities were compared with the video measurements, Figure 7. It was observed that the powder avalanche was ahead of the dense flow which is reflected in the simulation front velocities. As for the video data, the simulation front velocities were calculated by integrating the front position over a time interval. Apart from an initial instability when presumably the powder cloud is very small, the simulated and recorded avalanche front velocities show surprisingly good agreement.

The simulated avalanche mass balance (Figure 8) demonstrates the contrast between this avalanche and the previous two examples. Both the dense flowing and powder avalanches contain a significant proportion of the total avalanche mass; this triples over its course from the entrainment of snow and air. 


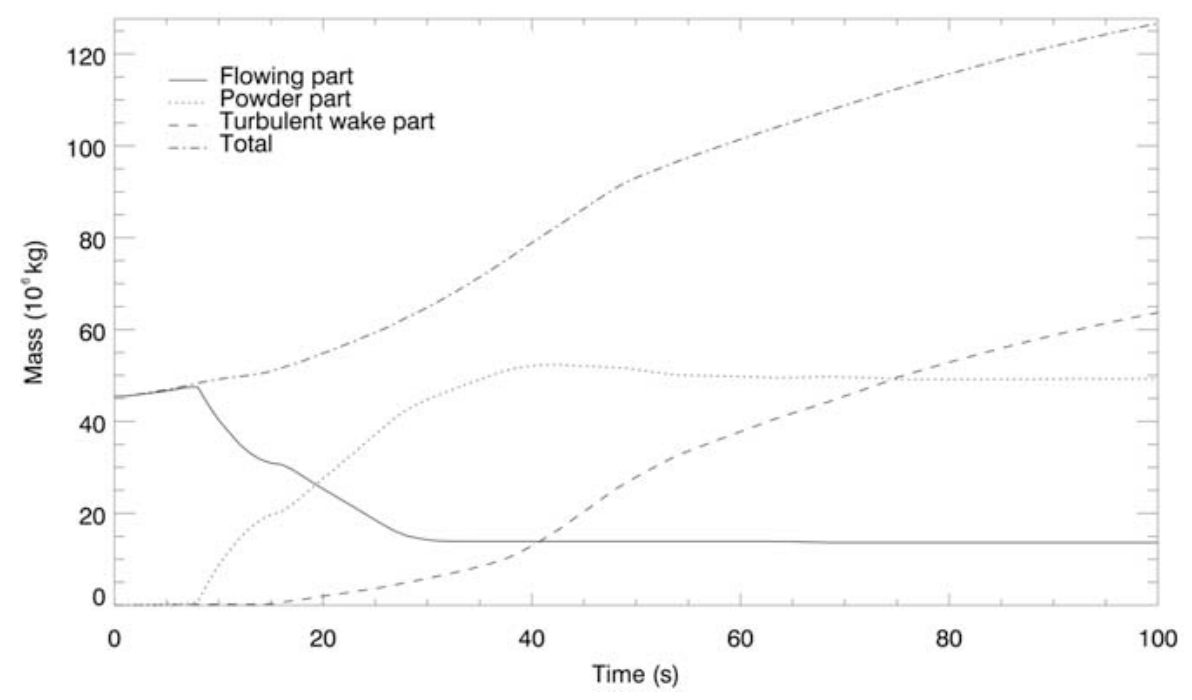

Figure 8. Simulated mass balance of Vallée de la Sionne avalanche, February 10, 1999. $E_{f p}=5 * 10^{-3}, E_{a p}=0.65$.

\section{Conclusion}

It has been shown that the one-dimensional motion of a mixed flowing/powder snow avalanche can be described by numerically solving depth averaged mass, momentum and energy conservation equations. A variety of information such as velocity measurements, impact pressure estimations, video and field analysis was compared with simulation results. From these comparisons ranges were put on mass exchange parameters $E_{f p}$ and $E_{a p}$. The contrast between different types of avalanche was demonstrated by the simulated mass balances of three avalanches in Aulta, Galtür and Vallée de la Sionne.

\section{References}

Bartelt, P., Salm, B., and Gruber, U.: 1999, 'Calculating Dense-Snow Avalanche Runout Using a Voellmy-Fluid Model with Active/Passive Longitudinal Straining', J. Glaciol. 45(150), 242-254.

Bonnecaze, R. T., Huppert, H. E., and Lister, J. R.: 1993, 'Particle-driven Gravity Currents', J. Fluid Mech. 88, 223-240.

Christen, M., Bartelt, P., and Gruber, U.: 2002, 'AVAL-1D: An Avalanche Dynamics Program for the Practice', International Congres INTERPRAEVENT 2002 in the Pacific Rim-Matsumoto/Japan, Congress Publication (2), pp. 715-725.

Dent, J. D.: 1993, 'The Dynamic Friction Characteristics of a Rapidly Sheared Granular Material Applied to the Motion of Snow Avalanches', Ann. Glaciol. 18, 215-220.

Dufour, F., Gruber, U., Bartelt, P., and Ammann, W.: 2000, 'Overview of the 1999 Measurements at the SLF Test Site, Vallée de la Sionne', ISSW Conference Proceedings, A Merging of Theory and Practice, pp. 527-534. 
Gubler, H., Hiller, M., Klausegger, G., and Suter, U.: 1986, 'Messungen an Fliesslawinen', Mitteilungen des Eidgenössischen Institutes für Schnee- und Lawinenforschung, Zwischenbericht.

Margreth, S.: 2000, 'Gutachten betreffend Unglückslawinen in Galtür vom 23.2.99 und in Valzur vom 24.2.1999', SLF Gutachten, G2000.12; 15-18.

Norem, H., Irgens, F., and Schieldrop, B.: 1987, 'A Continuum Model for Calculating Snow Avalanche Velocities', Avalanche Formation, Movement and Effects, Proceedings of the Davos Symposium, Sept. 1986, IAHS-Publ. No. 162.

Parker, G., Fukushima, Y., and Pantin, H. M.: 1986, 'Self-accelerating Turbidity Currents', J. Fluid Mech. 171, 145-181.

Sartoris, G. and Bartelt, P.: 2000, 'Upwinded Finite Difference Schemes for Dense Snow Avalanche Modelling', Int. J. Numer. Meth. Fluids 32, 799-821.

Simpson, J. E.: 1997, Gravity Currents, in the Environment and the Laboratory, Cambridge University Press, ISBN 0521664012.

Sovilla, B. and Bartelt, P.: 2002, 'Observations and Modelling of Snow Avalanche Entrainment', Natural Hazards and Earth System Sciences 2, 169-179.

Turnbull, B. and Bartelt, P.: 2002, 'A One-dimensional Mixed Flowing/Powder Snow Avalanche Model', Proceedings of the Fifth World Congress on Computational Mechanics, Vienna, July. 
